\title{
Conceitos de Ciência e a Política Cientificter, Tecnológica e de Inovação
}

LÉA VELHO"

\section{Resumo}

Este artigo busca contribuir para o debate sobre a ocorrência de um processo de internacionalização da Política Científica, Tecnológica e de Inovação (PCTI), ou seja, um processo em que diferentes países adotam as mesmas visões de PCTI, os mesmos instrumentos e formas semelhantes de gestão da PCTI. O debate aponta que a difusão destas ideias ocorre através das relações internacionais em $\mathrm{PCTI}$, isto é, contatos no nível internacional, mediados por organizações internacionais e organismos multilaterais (além da consciência dos autores dos trabalhos uns dos outros). $\mathrm{O}$ argumento central que se desenvolve aqui é que a evolução histórica da PCTI está fortemente correlacionada com a evolução do conceito dominante de ciência. Em outras palavras, o foco, os instrumentos e as formas de gestão que definem a PCTI num determinado momento são estreitamente relacionados com o conceito dominante de ciência. Na medida em que o conceito dominante de ciência tende a ser internacional, também as políticas de CTI que tal conceito suscita são internacionais. E é exatamente a relação entre conceito de ciência e a lógica da PCTI que se constitui no que se chamou, neste texto, de paradigmas da política científica e tecnológica.

Palavras-chave: Ciência. Política científica. Paradigma.

\footnotetext{
* Professora Titular do Departamento de Política Científica e Tecnológica da UNICAMP velho@ige.unicamp.br
} 


\section{Introdução}

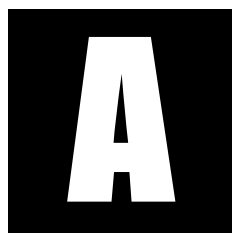

s similaridades entre as políticas públicas nacionais voltadas à Ciência, Tecnologia e Inovação (doravante CTI) dos mais variados países têm sido constantemente apontadas e registradas por uma série de analistas e estudiosos da questão. ${ }^{1}$ Argumenta-se que, desde o início do processo de institucionalização da Política de CTI em meados do século XX e até hoje, as bases conceituais, a estrutura organizacional, os instrumentos de financiamento e as formas de avaliação dos mesmos são comuns aos países que desenharam e implementaram políticas explícitas para estimular a produção e utilização de conhecimento científico e tecnológico.

Tais similaridades são convencionalmente atribuídas a dois fatores relacionados entre si. O primeiro refere-se à transformação radical da percepção e da imagem que o público tem da ciência e de seus impactos, a partir do final da Segunda Guerra. O fato que marca essa mudança de percepção é a crença de que, com dinheiro suficiente e uma massa crítica de pesquisadores de alto nível trabalhando sobre os novos avanços teóricos em disciplinas básicas, é possível resolver, em pouco tempo, o que antes eram problemas sem solução. Dickson (1988:3) refere-se a esse processo de transformação radical da imagem pública da ciência como sendo a construção de uma confiança quase religiosa nas possibilidades de que o conhecimento científico atuasse no equilíbrio de poder entre as nações, visando a objetivos econômicos e sociais. A ciência passou, assim, a desempenhar, no nível ideológico, um papel estratégico como força produtiva,

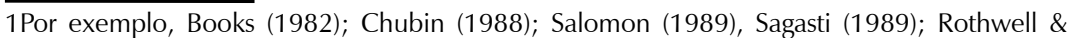
Dodgson (1992); Ruivo (1994), Bozeman (1994); Rip (1994); Elzinga \& Jamison (1995); Dodgson \& Bessant (1996); Dagnino \& Thomas (1999); Laredo \& Mustar (2001); Velho (2004). 
merecendo um lugar na política dos governos, que começaram a buscar formas de dirigir os efeitos da pesquisa a objetivos definidos. O resultado foi a formulação de políticas científicas nacionais centradas em modelos normativo-institucionais específicos nos países que saíram vitoriosos da Segunda Guerra, com destaque para os Estados Unidos e o Reino Unido.

Pouco a pouco, e esse é o segundo fator, tanto a imagem pública da ciência quanto o modelo normativo-institucional passaram a ser adotados pelos governos da maioria dos países industrializados (Salomon, 1977:49) e também pelos países em desenvolvimento, particularmente os latino-americanos (Oteiza, 1992:119). Em ambos os casos, os organismos internacionais (OCDE para os industrializados e OEA e UNESCO para os latino-americanos) tiveram papel preponderante no processo de internacionalização das políticas de CTI.

Após esse início, que alguns autores denominaram de infância das políticas da ciência (Salomon, 1977:51), as políticas e seu arcabouço conceitual, seus instrumentos e modos de avaliação evoluíram e se modificaram, mas o processo imitativo se preservou. Assim, quando se analisam as diversas fases da política científica nos mais variados países, percebe-se que estas se repetem e se organizam de forma semelhante (Rothwell \& Dodgson, 1992; Braun, 2003).

Até recentemente, essa imitação ou isomorfismo da Política de CTI não era vista como problema. ${ }^{2}$ Acreditava-se que um modelo único servia bem a todos (one size fits all, nas palavras de Di Maggio \& Powell, 1983: 147). Os advogados da tese da convergência apontavam para a

$2 \mathrm{O}$ processo de imitação de políticas tem sido denominado de diversas maneiras: Oteiza (1992) chamou-o de transferência de modelos institucionais; Di Maggio \& Powell (1983), de isomorfismo; Amadeo (1978) refere-se ao processo como "extrapolação" e ao modelo como "receita"; Salam \& Kidwai (1991) deram nome de blue print ao modelo de políticas imitado dos países industrializados em todo o então chamado Terceiro Mundo; Bastos e Cooper (1995) chamam o processo de emulação; Dagnino \& Thomas (1999) desenvolveram o conceito de transdução para explicar o mesmo fenômeno. 
globalização crescente da economia e dos sistemas de pesquisa, que colocam temas e demandas semelhantes para as políticas nacionais de CTI, assim como para as pressões normativas exercidas por organizações internacionais (OCDE, OMC e WIPO, entre outras) na definição de objetivos e medidas de tais políticas (Lemola, 2002; Braun, 2003).

Entretanto, vozes alertando para os problemas da imitação começaram a ser ouvidas na última década. ${ }^{3}$ Estas argumentam que, mesmo num contexto de interdependências internacionais e objetivos comuns de desenvolvimento, os diferentes países estão em diferentes estágios na sua transição para uma "sociedade baseada no conhecimento" , devido aos diferentes níveis de desenvolvimento econômico em que se encontram e às suas respectivas competências e capacidades para produzir e usar conhecimento. Além disso, os vários países têm diferentes visões de como desenvolver uma sociedade baseada em conhecimento devido, em parte, às histórias, às tradições, às estruturas institucionais, aos valores culturais e aos estilos de governo de cada um. Em vistas disso, era de se esperar que cada país concebesse políticas específicas, cada um enfatizando aspectos particulares do complexo processo de transformação em direção a uma sociedade baseada no conhecimento, ao invés de imitarem uns aos outros. Obviamente, isso não significa que um país não pode aprender com a experiência do outro, mas sim que a imitação (ou isomorfismo da política) não deve ser a regra.

Como decorrência dos questionamentos apontados, instalou-se um debate importante nos estudos de Política de CTI nos anos recentes. Alguns defendem que nem mesmo a tão propalada convergência de

3 Ver, por exemplo: Elzinga \& Jamison (1995); Dagnino \& Thomas (1999); Guston (2000); Kuhlman (2001); Laredo \& Mustar (2001); Velho (2004).

4 "Sociedades baseadas em conhecimento" foram definidas de várias maneiras, mas todas elas convergem para a concepção de uma sociedade diretamente baseada na produção, distribuição e uso do conhecimento e da informação, e na qual todas as atividades e políticas têm um conteúdo central de conhecimento. 
políticas existe de fato. Estes alegam que similaridades existem no nível da racionalidade da política e de alguns instrumentos adotados, mas que, na prática, cada país coloca mais ênfase ou maior peso em instrumentos diferentes, aloca recursos com base em critérios ajustados ao seu próprio sistema e tem estruturas diversas de gestão pública da CTI e organismos diferenciados de financiamento. Na medida em que os tomadores de decisão estão submetidos a diferentes estruturas organizacionais, eles adotam diferentes respostas às mesmas questões (Elzinga \& Jamison, 1995). Outros discordam, e atribuem o insucesso das políticas de $\mathrm{CTI}$, principalmente nos países latino-americanos (em particular o Brasil), ao fato destes terem simplesmente imitado as políticas e instrumentos dos países industrializados (Alcorta \& Peres, 1998; Dagnino \& Thomas, 1999; Tigre at al, 2001) .

O debate também inclui as razões da similaridade (ou diferenças) entre as políticas nacionais de CTI, assim como a extensão em que essas políticas evoluíram na mesma direção nos últimos anos e a importância das especificidades nacionais na escolha dessa direção. A relevância do debate reside no fato de que uma melhor compreensão dos processos passados pode ter um impacto considerável nos modelos futuros de governança para a política de CTI em todo o mundo.

É neste contexto que se insere este texto. O objetivo é contribuir para o debate partindo da posição de que existe um processo de internacionalização da Política de CTI, ou seja, diferentes países adotam as mesmas visões de Política de CTI, os mesmos instrumentos e formas semelhantes de gestão da Política de CTI. A difusão destas ideias ocorre através das relações internacionais em Política de CTI, isto é, contatos no nível internacional, mediados por organizações internacionais e organismos multilaterais (além da consciência dos autores dos trabalhos uns dos outros). O argumento central que se desenvolve aqui é que a evolução histórica da Política de CTI está fortemente correlacionada com a evo- 
lução do conceito dominante de ciência. Em outras palavras, o foco, os instrumentos e as formas de gestão que definem a Política de CTI num determinado momento são estreitamente relacionados com o conceito dominante de ciência. Na medida em que o conceito dominante de ciência tende a ser internacional, também as políticas de CTI que tal conceito suscita são internacionais. E é exatamente a relação entre conceito de ciência e a lógica da Política de CTI que se constitui no que se chamou, neste texto, de paradigmas da política científica e tecnológica.

Para atingir o objetivo e desenvolver o argumento, o texto se organiza em quatro seções, cada uma correspondendo a um dos quatro, aqui denominados, Paradigmas da Política de CTI, quais sejam: Ciência como Motor do Progresso; Ciência como Solução e Causa de Problemas; Ciência como Fonte de Oportunidade Estratégica; Ciência para o Bem da Sociedade. Para cada um desses paradigmas, que se desenvolveram num período histórico específico, se apresentam o conceito dominante de ciência e outras categorias de análise derivadas do conceito, tais como: quem produz conhecimento científico; a visão da relação entre ciência, tecnologia e sociedade; a racionalidade (ou lógica) e o foco da política de CTI; os instrumentos de análise de políticas e de avaliação implementados. O que se procura, com essa estrutura de apresentação, é desenvolver o argumento, já mencionado acima, de que é o conceito dominante de ciência que "modela" a lógica da política de CTI em cada paradigma.

A associação entre o conceito de ciência e as outras categorias analíticas, incluindo a lógica e o foco da política de CTI, está apresentada de maneira esquemática nos dois quadros abaixo. Estes esboçam o conteúdo de cada seção que será desenvolvida a seguir. 
Sociologias, Porto Alegre, ano 13, no 26, jan./abr. 2011, p. 128-153

\begin{tabular}{|c|c|c|c|c|}
\hline 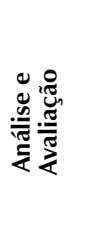 & \multicolumn{3}{|c|}{ 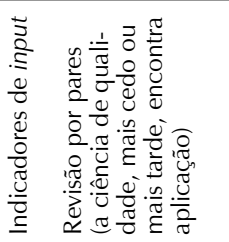 } & 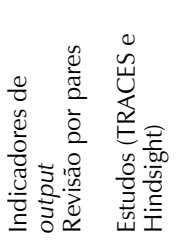 \\
\hline 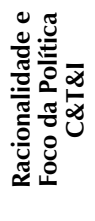 & \multicolumn{3}{|c|}{ 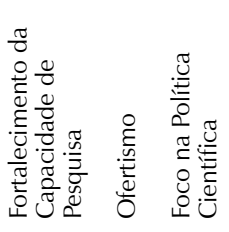 } & 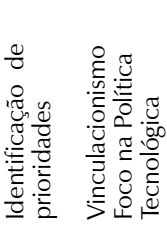 \\
\hline 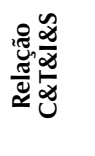 & \multicolumn{3}{|c|}{ 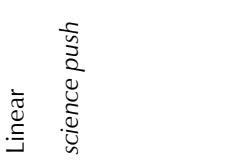 } & 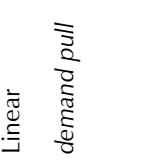 \\
\hline 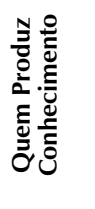 & \multicolumn{3}{|c|}{ 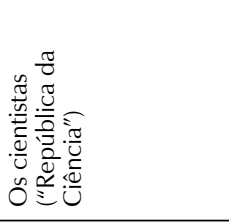 } & 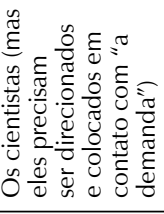 \\
\hline 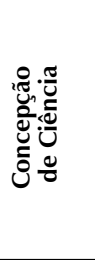 & 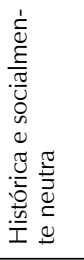 & 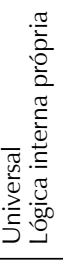 & & 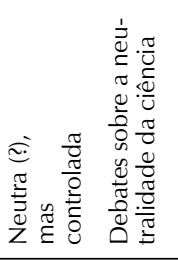 \\
\hline 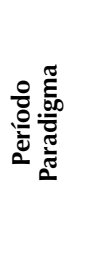 & 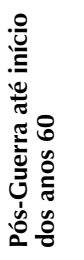 & 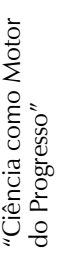 & & 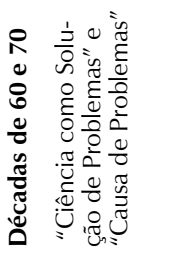 \\
\hline
\end{tabular}


Sociologias, Porto Alegre, ano 13, no 26, jan./abr. 2011, p. 128-153

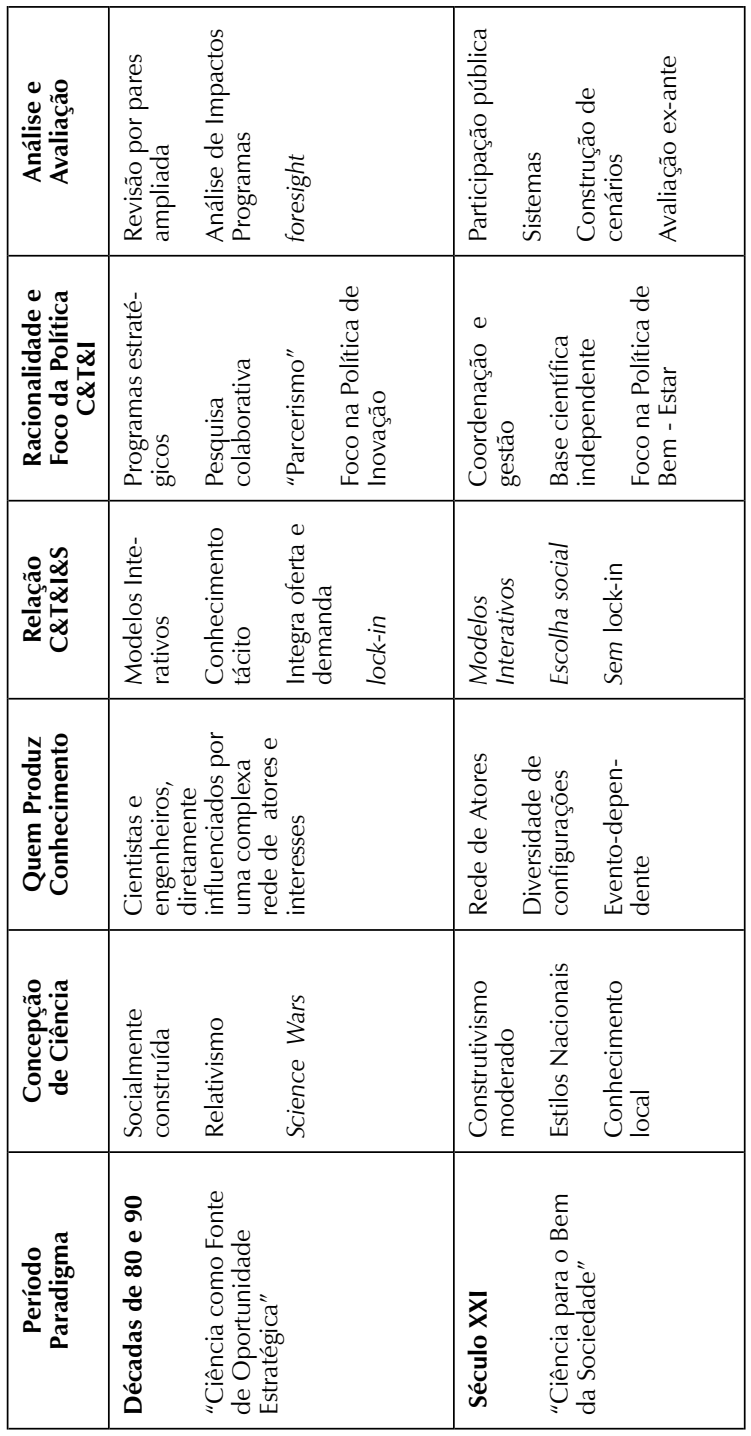




\section{A Ciência como Motor do Progresso - Pós-Guerra até início dos anos 60}

Esse paradigma é marcado pelo conceito de autonomia da ciência. A comunidade científica proclama a ciência fora dos processos sociais e, consequentemente, libera a si própria de qualquer responsabilidade pelo uso dado aos resultados de pesquisa. Depois do desenvolvimento de matança mais ou menos industrializada na Primeira Guerra, do papel da ciência e da tecnologia na construção do aparato militar fascista do período entreguerras, a Segunda Guerra Mundial chocou a comunidade científica. Muitos cientistas tinham as mãos sujas e existia uma ansiedade particular sobre as implicações morais do Projeto Manhattan, que desenvolveu armas nucleares. Parecia, então, que a ciência poderia se ligar a ideologias e projetos políticos. Poderia existir uma "ciência nazista", ou uma ciência socialista, e isso deu nova força a um velho debate sobre a autonomia da ciência em relação à sociedade. Membros influentes da comunidade científica começaram a se distanciar da aplicação da ciência e a focar no que começou a ser chamado de "ciência básica" (parece estranho para nós que vivemos com esse termo a vida toda, mas a ideia de ciência básica é relativamente nova na história da ciência).

Movimentos importantes na filosofia da ciência fizeram um paralelo com e forneceram a justificativa para essa definição de ciência como "básica" e separada da sociedade. Karl Popper, por exemplo, no seu livro lançado em 1951 - The Open Society and Its Enemies -, tenta estabelecer a base filosófica da independência e objetividade da ciência, colocando-a fora do alcance dos governos totalitários e, analogamente, de qualquer outra forma de interferência social.

Essa concepção de ciência, como busca da verdade através da razão e da experimentação, com o objetivo de garantir a extensão do conhecimento verificado (conforme Merton [1938],1973), também coloca o con- 
teúdo do conhecimento fora dos limites da análise sociológica. De acordo com essa concepção, o conhecimento científico só pode ser produzido por cientistas especificamente treinados para produzir conhecimento objetivo. Para justificar que pessoas carregadas de interesses, e sujeitas às relações sociais e influências culturais mais variadas sejam capazes de produzir conhecimento objetivo é fundamental a contribuição seminal de Robert Merton sobre as normas da ciência. Estas, que são chamadas de universalismo, comunismo, desinteresse, ceticismo organizado, modelam e normatizam o comportamento esperado dos membros da comunidade de pesquisa para garantir a produção de conhecimento livre de valores e de influências sociais. Para o trabalho de Merton contribuíram vários de seus discípulos, que estenderam as normas e as testaram empiricamente (Norman Storer, Barber, Jonathan e Steven Cole, Harriet Zuckerman).

Além de objetiva, a ciência é vista como a base, a origem da tecnologia. Esta, por sua vez, é uma forma de conhecimento subordinada, dependente da ciência. O processo de transformação do conhecimento científico em tecnologia e sua apropriação pela sociedade são concebidos de forma linear, iniciando-se com a ciência até produzir bem-estar social (ciência básica, ciência aplicada, desenvolvimento tecnológico, inovação, difusão da inovação, crescimento econômico e benefício social). Por essa razão, esse paradigma foi denominado de "ciência como motor do progresso"; tudo se inicia com a ciência.

Uma das principais evidências desta visão da relação entre CTI e sociedade foi o documento elaborado por Vannevar Bush, a pedido do Presidente Roosevelt dos EUA - entregue ao Presidente Truman, em 1945, e que se constituiu, posteriormente, em um símbolo desta concepção: o célebre Science: the Endless Frontier. Nele se detalha o fundamento do chamado modelo linear de inovação, em que se idealizava a ciência como uma "fronteira sem fim". Estes conceitos passaram a ser a base de 
um novo contrato social entre a comunidade científica e o Estado (Ronayne, 1984). Essa visão exprime uma fé quase religiosa na ciência, no poder da ciência para a solução de problemas (Dickson, 1988:3).

Chamada de Infância das Políticas de Ciência (Salomon, 1977), de Época Dourada dos Cientistas (Rip, 1994) e de Período da Ingenuidade (Brook's Report, 1982), esta fase da Política de CTI se caracteriza por recursos (financeiros e humanos) em crescimento exponencial (Price,1963). Nessa fase, o Estado, como principal financiador da ciência, delegava esta tarefa aos conselhos de pesquisa e essas delegavam as principais decisões aos próprios cientistas - os únicos juízes competentes. A necessidade de prestar contas à sociedade perdia sua importância quando confrontada com o argumento de que o sistema de revisão por pares estava selecionando a melhor pesquisa, e isto era o que o governo (e a sociedade) desejava (ou deveriam desejar). A comunidade científica, então, tinha grande autonomia na distribuição de recursos, prestava contas apenas a si própria e não se sujeitava a qualquer controle social direto.

O foco da Política de CTI, dada a concepção de ciência, era o fortalecimento da atividade de pesquisa e formação de recursos humanos (crescimento da ciência e da capacitação), o que se convencionou chamar de política com ênfase na oferta, ou Política Científica Ofertista (Herrera, 1973). Os atores principais, quase exclusivos, da Política de CTI são os próprios pesquisadores e o principal instrumento de financiamento são projetos individuais e de livre escolha, submetidos aos Conselhos de Pesquisa por iniciativa dos pesquisadores.

A avaliação da política de CTI e seus instrumentos se dava no nível micro, isto é, no do projeto individual submetido pelo pesquisador (ex ante) e no do desempenho do pesquisador, principalmente através de suas publicações (ex post). A avaliação se fazia, exclusivamente, pelo processo de revisão dos pares, tanto pelo controle da qualidade quanto do 
sistema de recompensa. Acreditava-se que a seleção cuidadosa daqueles pares competentes para julgar era garantia da excelência e da imparcialidade do sistema.

\section{A Ciência como Solução e Causa de Problemas - Décadas de 60 e 70}

Os movimentos sociais e de contracultura do final dos anos 60 e início dos 70 constituíram-se em terreno fértil para o questionamento da autonomia da ciência e da visão unicamente positiva de seus impactos. Intelectuais escrevendo a partir de diversas perspectivas - tais como Lewis Mumford e Jacques Ellul - sugeriam que havia externalidades negativas associadas aos resultados e às aplicações da ciência e da tecnologia. Ao mesmo tempo, autores mais amplamente lidos - como a bióloga Rachel Carson, inspiradora do movimento ambientalista, e o precursor do movimento de consumidores, Ralph Nader - levantaram questões sérias sobre os riscos envolvidos nas tecnologias como DDT e o automóvel Corvair. Escritores populares como Theodore Roszak e Alvin Toffler também contribuíram para levar ao mundo acadêmico e ao público em geral o argumento de que a ciência e a tecnologia são inerentemente imbuídas de valores e frequentemente problemáticas em termos dos impactos que acarretam na sociedade. Foi neste contexto que a ciência e a tecnologia, assim como suas relações com a sociedade, se tornaram objeto de estudo, dando origem aos Estudos Sociais da Ciência e da Tecnologia. Esse contexto social foi fundamental para a mudança na concepção de ciência.

Assim, a hegemonia da versão da ciência "fronteira sem fim" passou a ser questionada Vietnã, os movimentos de trabalhadores que perdiam suas posições devido às novas tecnologias, a degradação do meio ambiente, a concentração de renda, eram apontados como evidência de que a ciência 
não era extrassocial e muito menos socialmente neutra. Isso levou a uma visão de que, ainda que o conteúdo da ciência seja livre de influências sociais, seu foco, sua direção e seu uso podem e devem ser controlados.

Nesta concepção de ciência que deve ser "dirigida", ainda são os cientistas que produzem conhecimento, mas eles devem fazê-lo preferencialmente em grupos, já que os problemas que têm que resolver exigem combinação de saberes e contato com o mundo real. Portanto, passou-se a acreditar que os pesquisadores não devem ter total autonomia para decidir sua agenda de pesquisa (que não é mais vista como preferentemente ditada pela lógica interna própria da ciência), mas devem ser levados a trabalhar em problemas relevantes para a sociedade (particularmente o mercado).

A relação entre ciência e tecnologia ainda era concebida como linear, mas agora com ênfase na demanda. Ou seja, não é mais a ciência que empurra a tecnologia (science push), mas o mercado, as necessidades dos usuários que puxam o desenvolvimento científico (demand pull). Nessa relação entre ciência e tecnologia, as empresas eram tidas como possuidoras de capacitação e habilidades para julgar as demandas do mercado, identificar oportunidades tecnológicas e articular necessidades e demandas. Portanto, as empresas saberiam até que tipo de ciência elas precisariam.

Em linha com essa visão, o foco da política era o de conceber incentivos para que os pesquisadores trabalhassem em problemas relevantes para o setor produtivo e o de criar oportunidades para transferência de tecnologia. Para atingir o primeiro objetivo, criaram-se instrumentos específicos para alocar recursos para áreas prioritárias (setoriais, principalmente energia, telecomunicações e outras ligadas à infraestrutura). Dado que os instrumentos de política buscavam dirigir o desenvolvimento científico, vinculando-o às necessidades tecnológicas, essa fase tem sido chamada como Política de C\&T Vinculacionista (Dagnino et al, 1996). Como as palavras-chave são "pesquisa para o desenvolvimento tecnológico", há uma 
mudança nos objetivos das principais agências financiadoras de pesquisa (os famosos Conselhos de Pesquisa criados no paradigma anterior) que passaram e ser responsáveis também, pelo menos nominalmente, pelo apoio ao desenvolvimento tecnológico. Ainda que os cientistas tenham continuado a ser os principais atores da política de CTI, eles tiveram que dividir o palco com servidores públicos (policy-makers) e com os políticos na definição das prioridades.

A revisão por pares continuou a ter um papel central na alocação de recursos e na avaliação, mas não mais único. Desenvolveram-se indicadores científicos de output como auxiliares à revisão por pares. Criaram-se unidades especializadas em avaliação tecnológica (technology assessment, como o Office for Technology Assessment - OTA, nos Estados Unidos) para, entre outras funções, identificar as carências em termos de conhecimento científico para o desenvolvimento tecnológico em vários setores. Com a implementação de programas complexos com missões concretas, desenvolveram-se metodologias de avaliação ex post por painéis compostos de especialistas e usuários. Preocupada com a perda de autonomia, a comunidade científica liderou uma série de estudos, hoje considerados clássicos, que procuraram evidenciar a importância da pesquisa básica para o desenvolvimento tecnológico - relatório TRACES e HINDSIGHT. ${ }^{5}$ Mas a perda da exclusividade da comunidade acadêmica nos processos de Política de CTI parecia irreversível.

5 O projeto TRACES (Technology in Retrospect and Critical Events in Science), contratado pela National Science Foundation ao Illinois Institute of Technology Research Institute, buscava documentar que inovações tecnológicas consideradas fundamentais não teriam sido possíveis sem a pesquisa básica que lhes deu fundamento e que havia sido desenvolvida nas universidades. De certa forma, foi uma tentativa de se contrapor aos resultados do projeto Hindsight, realizado sob os auspícios do Department of Defense $(\mathrm{DoD})$ dos EUA, que buscava evidenciar a importância da pesquisa direcionada realizada pelos laboratórios e institutos públicos. Há uma extensa literatura sobre os dois projetos, mas uma análise comparativa e informativa pode ser lida em Thompson (1969). 


\section{A Ciência como Fonte de Oportunidade Estratégica - Décadas de 80 e 90}

Os processos de globalização da economia, a ideologia da liberalização (privatização, desregulamentação, redução ou remoção de subsídios e de barreiras tarifárias e não tarifárias ao comércio internacional, atração de investimento direto estrangeiro), inspirada no Consenso de Washington, são o cenário em que se desenvolveu uma nova concepção de ciência.

O grande número de pesquisadores trabalhando fora do sistema acadêmico (mais de 70\% nos países industrializados) levou vários autores a questionar o compromisso dos cientistas com as normas Mertonianas (Webster 1991; Mulkay, 1979). O argumento baseava-se em pesquisas empíricas que demonstravam que, na verdade, ao contrário de exibirem compromisso com as normas da ciência descritas por Merton e seus seguidores, os cientistas mostravam um notável distanciamento desse tipo de conduta. Outros autores apontavam a ausência de uma sociologia do conhecimento científico (Barnes, 1974; Bloor, 1976; Mulkay, 1979) e queriam entender os processos que ocorrem dentro da "caixa-preta" da produção do conhecimento, para cuja finalidade foram criados vários programas empíricos. Tais programas enfatizam a natureza contingente e socialmente localizada dos fatos científicos, adotam uma perspectiva relativista e concebem a ciência como construção social. ${ }^{6}$

6 Os principais programas de pesquisa desenvolvidos com esse objetivo são: o programa "forte" de Edinburgo, o "relativismo de Bath" e os chamados "estudos de laboratório". Uma apresentação geral desses programas pode ser encontrada em Knorr-Cetina \& Mulkay (1983). Estudos empíricos que usam o referencial desses programas conformam uma variada e extensa literatura publicada, sobretudo, nos periódicos Social Studies of Science e Science, Technology and Human Values. Ao longo destes anos, vários outros autores modificaram aspectos dos programas originais e constituíram outros programas de pesquisa. A principal característica comum a todos eles programas é a visão da ciência como socialmente construída, cujo conteúdo está sujeito à análise sociológica, assim como seu foco, sua direção e seu uso. 
Essa nova concepção de ciência é fortemente rejeitada pelos pesquisadores das áreas de ciências naturais - que ainda veem a si próprios como produtores de conhecimento objetivo e livre de influências sociais -, e estabelece-se o que se chamou de Science Wars (Gross \& Levitt, 1998). Existem aspectos consensuais e controvertidos dessa nova concepção de ciência e os debates ainda estão em andamento. Não é o caso de apresentar esses debates aqui, mas vale enfatizar que a noção de ciência como socialmente construída está cada vez mais aceita, se não pelos próprios cientistas, pelos analistas de CTI e pelos tomadores de decisão (até porque essa visão atende melhor aos interesses desses últimos).

Sendo colocada na estrutura social, a produção de conhecimento se dá em locais multivariados (empresas, hospitais, ONGs, além do sistema acadêmico). Reconhece-se que o conhecimento é produzido na interface de relações entre agentes múltiplos. Além disso, estudos indicam que outros modos de produção de conhecimento, de características multidisciplinares, que se dão no contexto de aplicação, parecem se tornar cada vez mais importantes e prevalecentes (Gibbons et al, 1994). Assim, a unidade básica de produção de conhecimento não é mais a comunidade científica, mas as chamadas comunidades transepistêmicas (Knorr-Cetina, 1983).

$\mathrm{Na}$ tentativa de integrar oferta e demanda, desenvolveram-se diversos modelos explicativos da relação entre CTI e Sociedade, todos eles com ênfase na interação entre os vários atores que podem se articular para produzir e usar conhecimento novo. Os principais modelos e propostas são: Modo 1 e Modo 2 (Gibbons et al, 1994); sistemas nacionais de inovação (Freeman, 1995; Nelson, 1993; Lundvall, 1992); hélice tripla (Etzkowitz \& Leydesdorff, 2000); construção social da tecnologia (Bijker, 1995); teoria do ator-rede (Latour \& Woolgar, 1979; Latour, 1988; Callon, 1987). É comum em todos os modelos a ideia de que produção de conhecimento e estrutura social são intimamente relacionadas, ao ponto de 
não se saber onde começa a C\&T e termina a sociedade e vice-versa. Não há, portanto, separação possível.

A abordagem associada aos modelos sistêmicos, interativos, está sendo absorvida por analistas e formuladores ou executores de política. Os instrumentos de financiamento buscam apoiar projetos interdisciplinares e interinstitucionais (atores trabalhando em contextos institucionais diversos), com destaque para programas de colaboração entre o setor público de pesquisa e o setor privado. Atores principais agora envolvem, além de pesquisadores, também os políticos e servidores públicos, economistas, especialistas em marketing, industriais - até a composição dos comitês e painéis para alocação de recursos e avaliação da Política de CTI reflete essa multiplicidade de atores sociais. Novos instrumentos que autorizam, por exemplo, a concessão de subvenções econômicas a empresas para a realização de atividades de $P \& D$ e inovação tecnológica rompem com os paradigmas anteriores vinculados ao modelo linear.

O "sucesso" de um instrumento de política não se mede mais apenas pelos resultados dos projetos financiados em termos de produção acadêmica (número de publicações e citações). Desenvolvem-se metodologias para estimar os impactos econômicos e sociais, assim como novos instrumentos para detectar oportunidades como foresight. Há um alargamento do sistema de revisão por pares, incorporando atores fora do sistema científico.

\section{A Ciência para o Bem da Sociedade - Século XXI}

Esse é o paradigma que ainda está em construção, portanto, em competição com o anterior (Kuhn, 1962). Portanto, assim parte do texto é especulativa e preliminar. 
Quando se analisam os resultados das diretrizes internacionais adotadas pela grande maioria dos países devido à pressão do processo de globalização e de organismos internacionais (FMI, OMC e outros), encontram-se casos de sucesso e de fracasso. Existe uma tendência a questionar os processos de imitação de políticas públicas em geral, mesmo numa época em que todos os países têm que enfrentar pressões externas similares. Assim, há hoje uma retomada do enfoque "nacional", e até mesmo do local (think globally, act locally, no sentido usado por Stiglitz, 1993), e uma busca por políticas que considerem que a configuração de um sistema depende da sua história (é, portanto, path dependent ${ }^{7}$ ). Esse argumento implica levar em consideração as diferenças culturais, o desejo (diferenciado) das populações, a diversidade de formas de recursos (naturais, humanos e financeiros) disponíveis, incluindo o conhecimento, na elaboração de planos de desenvolvimento e políticas associadas.

À luz de tal contexto, a nova concepção de ciência que está sendo delineada admite que existem muitas formas diferentes de conhecimento e que estas se relacionam de forma variável e assimétrica. Isto não quer dizer que não exista qualquer forma de autoridade epistêmica, mas esta será sempre o resultado de uma produção coletiva, com os seus momentos de conflito, que permitirá determinar, de maneira situada, a hierarquia dos saberes e da respectiva autoridade em função da situação, dos problemas, das prioridades e das consequências esperadas de intervenções associadas a esses saberes. Ou seja, a ciência é culturalmente situada e construída, e

\footnotetext{
7 Path dependence (sem tradução adequada para o português) é um argumento geral que tem sido amplamente usado em ciência política (Pierson, 2000), sociologia histórica (Mahoney, 2000) e no estudo do desenvolvimento econômico e tecnológico (North, 1990; Arthur, 1994). No sentido amplo, a expressão significa que a configuração atual de um sistema depende de sua história e, por isso, não se pode compreendê-la analisando apenas seu estado atual. Num sentido mais restrito, ela tem sido usada como um processo de sequência histórica em que eventos contingentes provocam padrões institucionais ou uma cadeia de eventos que tem propriedades determinística
} 
incorpora conhecimentos locais, abrindo espaço para estilos nacionais de produção, ao lado dos universais. Esse é um debate ainda muito recente, que tem participação ativa de autores dos Estudos Sociais da Ciência (Fuller, 1999; Collins \& Evans, 2002; Santos, 2003; Jasanoff, 2004; Latour, 2005).

Nesta nova concepção de ciência que ainda toma contornos, não se nega que os pesquisadores tenham papel destacado, mas reconhece-se a participação de múltiplos atores, associados em redes de configuração variável, segundo o evento. Admite-se até mesmo a contribuição de grupos locais numa ecologia de práticas e saberes (Santos, 2003). O conhecimento se faz de forma predominantemente interdisciplinar e se dá nos locais mais variados.

A relação entre ciência, tecnologia e inovação continua a ser descrita através de modelos interativos, mas estes são mais complexos na medida em que os vínculos internos e externos são importantes, assim como as influências e atores múltiplos. A empresa deixa de ser o foco principal de escolha tecnológica, já que esta pode ser revertida por escolhas e influências sociais (por exemplo, a decisão social de alguns países europeus em banir a produção e o uso de organismos geneticamente modificados de seu território). Poderá tomar maior visibilidade a ideia de que CTI são instrumentos para atingir objetivos socialmente definidos.

O foco da Política de CTI é (ou deve vir a ser?) o bem-estar social. Para isso, cabe à política pública de CTI o papel de articulador, regulador e facilitador, garantindo a conectividade dos múltiplos atores (stakeholders). Desenvolvem-se instrumentos para garantir a participação social na definição de objetivos e instrumentos de política, assim como na disseminação de resultados (papel da mídia). A definição de políticas deve ocorrer não apenas no nível nacional, mas também nos níveis regionais e locais.

Há uma preocupação com o desenvolvimento de mecanismos de avaliação de impactos sociais com participação pública, além de revisão 
por pares ampliada. O controle de qualidade da CTI ocorre no contexto de aplicação e incorpora interesses sociais, econômicos e políticos. É importante enfatizar que a pesquisa no contexto de aplicação, com participação de usuários, pode e certamente inclui o desenvolvimento de pesquisa fundamental que combina relevância (para contextos específicos, possivelmente locais) e excelência acadêmica (o avanço da ciência mesma). Esse argumento é fortemente defendido por Rip (2002).

Avaliações sistêmicas são necessárias para avaliar processos sistêmicos, portanto, não é suficiente avaliar o desempenho, em separado, de cada ator da rede responsável por um determinado evento. Evidentemente, políticas que são tipicamente nacionais ou locais necessitam de modos de avaliação compatíveis, isto é, os métodos e indicadores não podem ser simplesmente copiados da "caixa de ferramentas" disponível nos outros países. Além disso, indicadores tipicamente usados para avaliar atividades de pesquisa disciplinares não se prestam para avaliação de pesquisa multidisciplinar. É fundamental desenvolver capacitação para o desenvolvimento de métodos e técnicas de avaliação compatíveis com a nova concepção de ciência e de sua relação com a tecnologia e processos de inovação

É difícil prever, de fato, a direção que a Política de CTI vai tomar em função da concepção de ciência que se tornar dominante. O que se descreve nesta seção, como indicado, é mais fruto de uma leitura particular dos eventos observados e de preferências políticas da autora.

\section{Considerações Finais}

Este texto partiu do reconhecimento de que existem similaridades marcantes na periodização usada por vários estudiosos de diferentes países para descrever a evolução da Política Científica, Tecnológica e de Inovação (CTI). Além disso, as características dessas periodizações exibem um 
alto grau de congruência. Este texto teve, então, o objetivo de explorar as causas dessa congruência e, ao fazer isso, desenvolveu o argumento de que a evolução histórica da Política de CTI está fortemente correlacionada com a evolução do conceito dominante de ciência. Ou seja, é o conceito dominante de ciência que "modela" a lógica da política de CTI. Além disso, como o conceito dominante de ciência variou desde que o aparato institucional para Política de CTI foi criado, também variou a lógica subjacente à Política de CTI. Desta forma, é possível identificar fases ou paradigmas no processo de evolução da política de CTI, cada um deles caracterizado por uma racionalidade derivada de uma concepção específica de ciência que define o foco, os instrumentos e as formas de gestão implementadas.

Para cada um desses paradigmas, que se desenvolveram num período histórico específico, se apresentaram o conceito dominante de ciência e outras categorias de análise derivadas do conceito, tais como: quem produz conhecimento científico; a visão da relação entre ciência, tecnologia e sociedade; a racionalidade (ou lógica) e o foco da política de CTI; os instrumentos de análise de políticas e de avaliação.

Evidentemente esse é um exercício analítico e, como tal, simplificador de uma realidade muito mais complexa. Tem-se consciência da linearidade do argumento e do fato de que algumas das categorias analíticas que se destacam provavelmente, na prática, são incompatíveis com a visão de ciência dominante no período analisado. Por exemplo, os instrumentos de avaliação usados até hoje pelas agências financiadoras de P\&D tendem a ser ainda aqueles dos paradigmas anteriores em que os indicadores acadêmicos prevaleciam. Mas é difícil dizer se isso é mantido assim porque não se desenvolveram ainda critérios e indicadores de qualidade coerentes com a visão de ciência dominante ou se é porque, de fato, não existe uma visão de ciência dominante na sociedade, mas várias visões. 
Tais limitações, entretanto, não invalidam o exercício aqui realizado. Acredita-se que a lógica desenvolvida é útil não apenas para analisar o passado como para pensar e planejar o futuro. Quanto a esse último, conceber a ciência como sendo socialmente construída, podendo ser direcionada pelas necessidades e preferências nacionais, realizada com a participação de múltiplos atores, certamente informaria políticas de CTI muito diferentes das atuais. Essa possibilidade é alentadora para os analistas de Política de CTI.

\section{The concept of Science, and the Science, Technology and Innovation Policy}

\section{Abstract}

This paper contributes to the debate on the occurrence of a process of internationalization of the Science, Technology and Innovation Policy - STIP, a process in which different countries adopt the same views of the STIP, the same instruments and similar forms of management of the STIP. The debate shows that the dissemination of these ideas occurs through the international relations in the STIP, i.e., contacts at the international level, mediated by international organizations and multilateral agencies (in addition to the authors' knowledge of the works of others). The central argument developed here is that the historical evolution of the STIP is strongly correlated with the evolution of the dominant conception of science. In other words, the focus, the instruments, and the forms of management that define the STIP in a given time are closely related to the dominant conception of science. Insofar as the dominant conception of science tends to be international, the policies of STI raised by this concept are likely to be international too. And it is this relationship between the concept of science and the logic of the STIP that constitutes what has been labeled, in this text, as the paradigms of science and technology policy.

Keywords: Science. Scientific policy. Paradigm. 


\section{Referências}

ALCORTA, L.; PERES, W. Innovation systems and technological specialization in Latin America and the Caribbean. Research Policy, v.26, p. 857-81, 1998.

ARTHUR, W. Increasing returns and path dependence in the economy. Ann Arbor: University of Michigan Press, 1994.

BASTOS, M. I.; COOPER, C. Politics of technology in Latin America. Londres: Routledge/UNU Press, 1995.

BIJKER, W. Of bicycles, bakelites, and bulbs: towards a theory of sociotechnical change. Cambridge, Mass: MIT Press, 1995.

BOZEMAN, B. Evaluating government technology transfer: early impacts of the cooperative technology paradigm. Policy Studies Journal, v.22, n.3, p. 322-7, 1994.

BRAUN, D. Last tensions in research policy-making: a delegation problem. Science and Public Policy, v.30, n.5, p.309-21, 2003.

CALLON, M. Society in the making: the study of technology as a tool for the sociological analysis. In: BIJKER, W. E.; HUGHERS, T. P.; PINCH, T. J. The social construction of technological systems: new directions in the sociology and history of technology. Cambridge: MIT Press, 1987. p. 83-106.

CHUBIN, D. E. Research evaluation and the generation of Big Sciece Policy. Knowledge: Creation, Diffucion, Utilization, v.9, n.2, p.254-77, 1988.

COLLINS, H.; EVANS, R. The third wave of science studies: studies of expertise and experience. Social Studies of Science, v.32, n.2, p.235-96, 2002.

DAGNINO, R.; THOMAS, H. La politica cientifica y tecnológica en América Latina. Redes, v. 12, n. 6, p. 49-74, 1999.

DAGNINO, R.; THOMAS, H.; DAVYT, A. El pensamiento en ciencia, tecnologia y sociedad en Latinoamérica: una interpretación de su trayectoria. Redes, v. 3, p.13-51, 1996.

DICKSON, D. The new politics of science. Chicago: The University of Chicago Press, 1988.

DI MAGGIO, P.; POWELL, W. The iron case revisited: institutional isomorphism and collective rationality. American Sociological Review, v.48, p.147-60, 1983.

DODGSON, M.; BESSANT, J. Effective innovation policy. Londres: Routledge/ International Thomson Business Press, 1996.

ELZINGA, A.; JAMISON, A. Changing policy agendas in science and technology. In: Jasanoff, S. et al. Handbook of science and technology studies. Londres: Sage, 1995. p. 572-97. 
ETZKOWITZ, H.; LEYDESDORDD, L. The dynamics of innovation: from national systems and Mode 2 to Triple Helix of university-industry-government. Research Policy, v.29, p.109-23, 2000.

FREEMAN, C. The national system of innovation in historical perspective. Cambridge Journal of Economics, v.19, n. 1, p.5-24, 1995.

FULLER, S. The governance of science: ideology and the future of the open society. Milton Keynes: Open University Press, 1999.

GIBBONS, M, et al. The new production of knowledge. Londres: Sage Publications, 1994.

GROSS, P. R.; LEVITT, N. Higher superstition: the academic left and its quarrels with science. Baltimore: The Johns Hopkins University Press, 1998.

GUSTON, D. Between politics and science. Cambridge: Cambridge University Press, 2000.

HERRERA, A. Social determinants of science policy in Latin America. In: Cooper, C. Science, technology and development. Londres: Frank Cass, 1973. p. 19-37. JASANOFF, S. States of knowledge: the co-production of science and social order. Londres: Routledge, 2004.

KNORR-CETINA, K. The ethnografica study of scientific work: towards a constructivist interpretation of science. In: KNORR-CETINA, K. D.; MULKAY, M. Science observed: perspectives on the social study of science. Londres e Beverly Hills: Sage, 1983. p. 115-40.

KNORR-CETINA, K.; MULKAY, M. Science observed: perspectives on the social study of science. Londres: Sage, 1983.

KUHLMAN, S. Governance of innovation policy in Europe: three scenarios. Research Policy, v. 30, n.6, p.953-76, 2001.

KUHN, T. The structure of scientific revolutions. Chicago: Chicago University Press, 1962.

LAREDO, P.; MUSTAR, P. Research and innovation policies in the new global economy: an international comparative analysis. Chelteham: Edward Elgar, 2001.

LATOUR, B.; WOOLGAR, S. Laboratory life: the social construction of scientific facts. Londres e Beverly Hills: Sage, 1979.

LATOUR, B. A relativistic account of Einstein's relativity. Social Studies of Science, v.18, p.3-44, 1988.

LATOUR, B. Reassembling the social: an introduction to actor network theory. Oxford: Oxford University Press, 2005. 
LEMOLA, T. Convergence of national science and technology policies. Research Policy, v.33, n. 3, p.1481-90, 2002.

LUNDVALL, B. A. National systems of innovation: towards a theory of innovation and interactive learning. Londres: Frances Pinter, 1992.

MAHONEY, J. Path dependence in historical sociology. Theory and Society, v.29, n.4, p.507-48, 2000.

MERTON, R. K. The normative structure of science. In: The sociology of science: theoretical and empirical investigations. Chicago: University of Chicago Press, 1973.

MULKAY, M. Science and the sociology of knowledge. Londres: George Allen \& Unwin, 1979.

NELSON, R. National innovation systems: a comparative analysis. Nova York: Oxford University Press, 1993.

NORTH, D. Institutions, institutional change and economic performance. Cambridge: Cambridge University Press, 1990.

OTEIZA, E. La politica de investigación cientifica y tecnológica argentina: história y perspectivas. Buenos Aires: Sociedad y Cultura, 1992.

PIERSON, P. Increasing returns, path dependence and the study of policitics. The American Political Science Review, v.94, n. 2, p.251-67, 2000.

RIP, A. Postmodern science and technology policy. In: NISTEP International Symposium on New Articulations of Science and Technology System. Tokyo: NISTEP,2002. mimeo.

RIP, A. The republic of science in the 1990s. Higher Education, v. 28, n. 1, p.323, 1994.

RONAYNE, J. Science in government. Londres: Edward Arnold, 1984.

ROTHWELL, R.; DODGSON, M. European technology policy evolution. Technovation, v.12, n.4, p.223-38, 1992.

RUIVO, B. Phases or paradigmas of science policy?. Science and Public Policy, v.21, n.3, p.157 -64, 1994.

SAGASTI, F. Science and technology policy research for development: an overview and some priorities from a Latin American perspective. Bulletin of Science, Technology and Society, v. 9, n.1, p. 50-60, 1989.

SALAM, A.; KIDWAI, A. A blueprint for science and technology in the developing world. Technology in Society, v.13, n.4, p.389-404, 1991. 
SALOMON, J-J. Science policy studies and the development of science policy. In: Spiegel-Rosing, I.; Solla Price, D. Science, technology and society: a crossdisciplinary perspective. Londres: Sage Publications, 1977.

SANTOS, B. S. Conhecimento prudente para uma vida decente: um discurso sobre as ciências revisitado. Porto: Afrontamento, 2003.

SALOMON, J-J. Critérios para uma política de ciência e tecnologia: de um paradigma a outro. Revista Colóquio/Ciências, p.90-8, 1989.

STIGLITZ, J. Thinking like an economist. In: STIGLITZ, J. Economics. Nova York: W.W.Northo and Co., 1993. p. 27-37.

THOMPSON, P. TRACES: basic research links to technology appraised. Science, v.24, p. 374-75, 1969.

VELHO, L. Research capacity building for development: from old to new assumptions. Science, Technology and Society, v.9, n. 2, p.172-207, 2004.

WEBSTER, A. Science, technology and society. Londres: Macmillan Education, 1991.

Recebido: 30/09/2010

Aceite final: 18/10/2010 